\title{
Universe in the Classroom: using robotic telescopes in primary schools
}

\author{
Sarah Eve Roberts ${ }^{1,2 *}$, Haley Gomez ${ }^{1}$, Edward Gomez ${ }^{1,2}$
}

\begin{abstract}
Universe in the Classroom is a science engagement programme that provides under-served Welsh primary schools with improved teaching methods and innovative tools, including access to robotic telescopes through the Las Cumbres Observatory (LCO), to modernise and enhance the way science is taught to young children aged 4-11 years. As a result, the programme has engaged with 133 primary schools from 21 of the 22 Welsh counties, $47 \%$ of whom receive below average budget per student per year. In addition to the provision of highquality resources, Universe in the Classroom offers teacher training workshops to improve teachers' scientific knowledge and confidence, with 75\% stating improved confidence using science resources post-training event. The programme has also engaged with of 22,083 schoolchildren, successfully improving their understanding of the Universe and challenging perceptions of scientists, with an additional $10 \%$ of girls describing scientists as female after a workshop hosted by our diverse and enthusiastic team of undergraduate role models. Furthermore, the number of complex scientific concepts discussed by students tripled postworkshop. Although we identified several potential deterrents affecting the uptake of robotic telescopes in primary school classrooms, these were addressed by the programme and $25 \%$ of teachers claim to have used the telescopes in their schools, with an additional $75 \%$ stating their school would find a second LCO account useful.
\end{abstract}

\section{Keywords}

primary education; science education; teacher training; role models; education resources; robotic telescopes; astronomy

${ }^{1}$ School of Physics and Astronomy, Cardiff University, Cardiff, UK CF24 3AA

${ }^{2}$ Las Cumbres Observatory Global Telescope Network, 6740 Cortona Dr. Suite 102, Goleta, CA 93117 *Corresponding author: seroberts@lco.global

\section{Introduction}

In 2015, Wales scored lower than all other UK nations for science in the International Programme for Student Assessment (PISA) study, this score is lower than the Organisation for Economic Co-operation and Development (OECD) average and has been falling since 2009 (National Assembly for Wales, 2016). A recent Estyn thematic report (Science in Key Stage 2 and 3) recommended the following to improve primary level engagement with Science, Technology,
Engineering and Mathematics (STEM) (Estyn, Welsh Government, 2013):

1. provide challenging science opportunities to stretch all pupils, particularly the more capable, and eliminate tasks that are too easy;

2. provide more opportunities for pupils to pursue their own scientific interests;

3. provide training for teachers with weak science subject knowledge; 
4. provide science continued professional development (CPD);

5. provide more professional development, support and advice to schools on science teaching and learning.

Beyond STEM subjects, the thematic report from Estyn identified other global concern areas for Wales including: "tackling aspiration, engagement, emotional skills, well-being and social mobility in schools in challenging circumstances (e.g. poverty, lack of engagement, lack of positive role models)."

In this landscape, Universe in the Classroom (UitC) was developed in 2014, with funding from the Welsh Government's National Science Academy, in partnership with Cardiff University, non-profit organisation Las Cumbres Observatory (LCO) and the award-winning, global Universe Awareness ${ }^{1}$ project.

UitC was designed to bring the unique inspirational qualities of astronomy to Welsh primary schools to improve STEM, raise primary school teacher participation in STEM activities all over Wales and introduce challenging learning opportunities for students. UitC aimed to do this by providing schools with high-quality educational resources and workshops, in particular to schools that may struggle to access them due to budget, language, or geographical restrictions.

Schools were provided access to the Las Cumbres Observatory robotic telescope network, along with a range of hands-on materials with complementary digital resources, to support the teaching of astronomy in primary schools.

Particular emphasis was placed on raising social mobility (improving social status), engagement and STEM skills in disengaged schools and underserved communities. The project also facilitated engagement between Welsh scientists and local communities by building a diverse team of scientists to run school workshops through an undergraduate (UG) and postgraduate (PG) role model scheme.

\footnotetext{
${ }^{1}$ www.unawe.org
}

\section{Universe in the Classroom Engagement Figures}

Between January 2014 and June 2017, UitC engaged with 205 Welsh primary school teachers and 22,083 schoolchildren (for a full breakdown of the project's reach see Table 1).

Table 1. Breakdown of Universe in the Classroom impact figures.

\begin{tabular}{|c|c|}
\hline Welsh primary schools engaged & 133 \\
\hline Welsh primary school teachers trained & 205 \\
\hline Classroom workshops hosted & 74 \\
\hline UG and PG role models trained & 50 \\
\hline $\begin{array}{c}\text { School children engaged } \\
\text { (classroom workshops, public } \\
\text { events and trained teachers) }\end{array}$ & 22,083 \\
\hline
\end{tabular}

\section{Participant School Demographic}

To maximise the impact of UitC, and ensure we were reaching typically less-engaged schools, in line with the first ESTYN recommendation to provide science opportunities to all pupils, schools were hand-picked based on the following defined criteria (a full breakdown can be seen in Table 2):

1. Schools with high percentage of students living in relative poverty, based on the free school meal (FSM) eligibility (Statistics for Wales, 2013a);

2. Schools with below-average levels of attainment in science at Key Stage 2 (Statistics for Wales, 2013b);

3. Schools with a low annual budget per student (Statistics for Wales, 2013b);

4. Welsh Medium schools (Welsh Assembly Government, 2007);

5. Geographic diversity (schools in North and West Wales);

6. Schools for students with special educational needs. 


\section{Student Attainment}

The primary target audience of UitC were schools with an above average percentage of pupils eligible for FSM (>30\%). A 2014 study by the Welsh Government's Statistics for Wales found that primary school pupils eligible for Free School Meals (FSM) consistently under-perform their non-eligible counterparts, with a lower percentage of FSM-eligible pupils achieving the expected level or above (Outcome 5 at Foundation Phase (ages 3-7), and Level 4 at Key Stage 2 (KS2, ages 7-11)) across subject areas, in English, Welsh, Mathematics and Science (Statistics for Wales, 2013b). The study provides evidence that relative poverty (based on FSM) has a notable effect on a child's educational performance, and $18.4 \%$ of children at schools in Wales are currently eligible for FSM (Office for National Statistics, 2017).

By targeting these schools, in addition to schools with $<60 \%$ students achieving the expected outcome at KS2, UitC aims to raise attainment levels in Wales from Foundation Phase through to Key Stage 2 and beyond.

\section{Lack of resources or engagement with Uni- versities}

In addition to combatting low attainment, UitC targeted schools in remote regions (specifically the North and West of Wales) and Welsh Medium schools. Schools from 21 of the 22 Welsh counties were engaged, as shown in the distribution of participant schools in Figure 1. Distance from working scientists (who generally cluster around large cities), in addition to lack of educational resources available in Welsh language, classifies these schools as underserved.

Of the schools engaged through UitC, 6 (4\%) were special schools in Southwest Wales. Special schools cater to children with special educational needs and disabilities. These schools actively contacted our project after hearing about us through teaching networks. This demonstrated significant enthusiasm by teachers in these schools. These schools fit into our chosen demographic of underserved and unengaged Welsh primary schools.

UitC actively engaged with underserved schools from the above list of criteria, including visiting the schools and delivering activities in their classrooms. As a result, primary schools from 21 of the 22 Welsh counties participate in the programme, $47 \%$ of whom receive below average budget per student per year.

\section{Universe in the Classroom}

Universe in the Classroom has four core parts:

1. Teacher training workshops;

2. Hands-on educational resources;

3. Robotic telescopes;

4. STARS role model programme and school workshops.

\section{Teacher Training Workshops}

The project aimed to provide schools with improved teaching methods and innovative tools to modernise and enhance the way STEM subjects (science, technology, engineering and mathematics) are taught to young children. These resources were disseminated through teacher training sessions, in line with final three ESTYN recommendations to support teachers with weak scientific knowledge. Since 2014, the programme has trained over 200 Welsh primary school teachers from 100 schools to use the new resources.

Selected schools are required to send at least one of their teachers to a UitC training event. During the period Jan 2014-June 2017, Universe in the Classroom trained 205 Welsh primary school teachers through a mixture of 17 full-day Continuing Professional Development (CPD) workshops and shorter ( 2-hour) twilight training sessions held at a variety of educational and scientific venues across Wales to ensure easy access to teachers in all counties. The venues included Universities, science centres and partner schools. Substitution cover was offered to participating schools ( $£ 150$ per school), and travel 

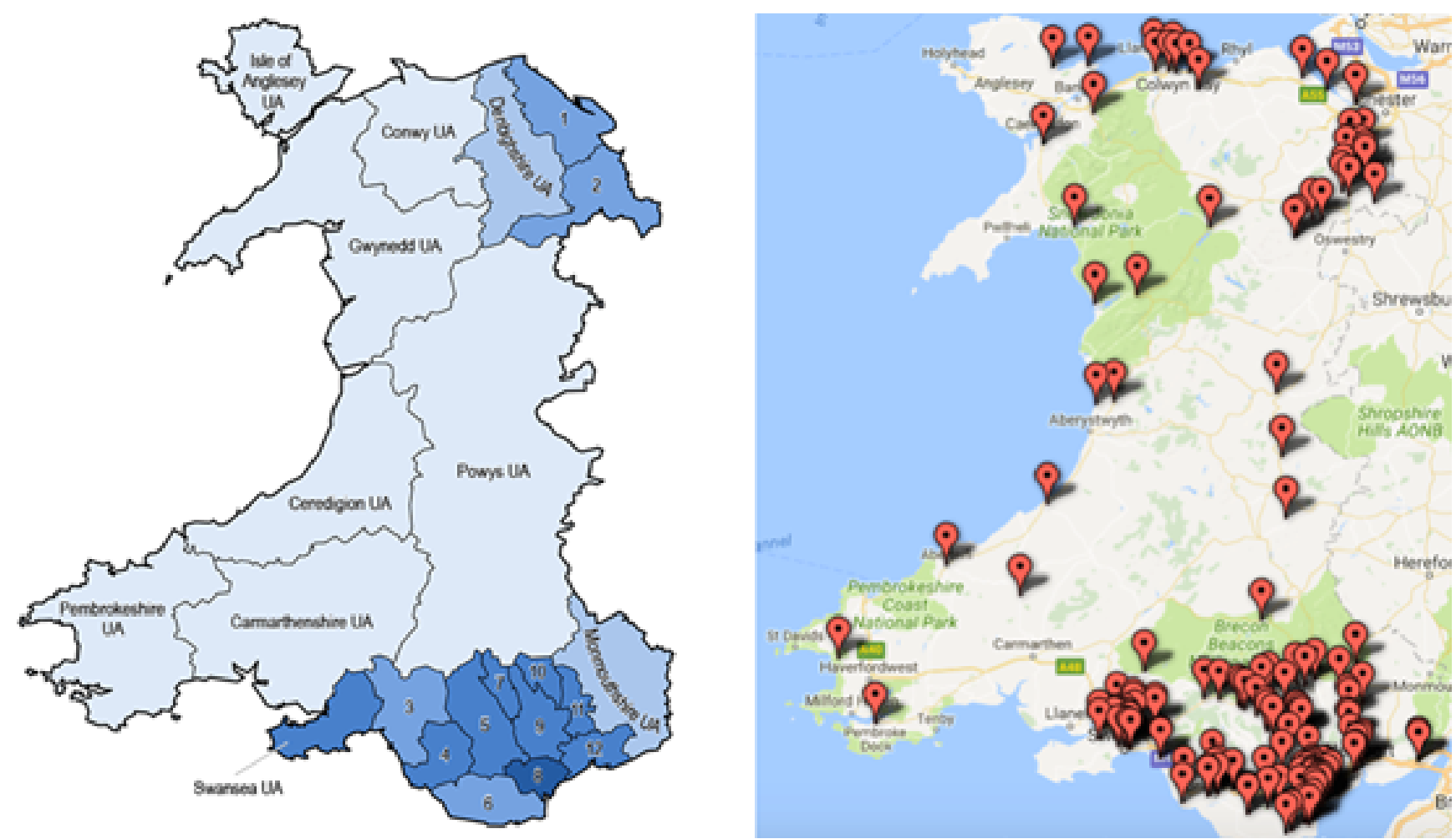

Figure 1. The right map shows the distribution of Universe in the Classroom participant schools. On the left is a Wales population density map based on data from the Office for National Statistics and Ordnance Survey data; darker shading corresponds to higher population density. Many of the UitC schools are clustered in the South, where the highest population density is seen. The full demographics are broken down in Table 2.

Table 2. Breakdown of Universe in the Classroom participant schools based on selection criteria. The majority of schools can be classified as eligible for the project based on two or more of the six defined criteria.

\begin{tabular}{|c|c|}
\hline Demographic & Number of participant schools \\
\hline $\begin{array}{c}\text { Schools with high percentage of } \\
\text { students eligible for Free School Meals }(>30 \%)\end{array}$ & $66(47 \%)$ \\
\hline Schools located in remote regions (North and West Wales) & $42(31 \%)$ \\
\hline $\begin{array}{c}\text { Schools with low percentage of students } \\
\text { achieving expected Level 4 grade at KS2 }(<60 \%)\end{array}$ & $43(28 \%)$ \\
\hline $\begin{array}{c}\text { State schools receiving a low } \\
\text { annual budget per student }(<£ 3000)\end{array}$ & $47(29 \%)$ \\
\hline Welsh Medium Schools & $26(18 \%)$ \\
\hline Special Schools & $7(5 \%)$ \\
\hline Schools matching none of the defined criteria & $9(6 \%)$ \\
\hline
\end{tabular}

costs were covered for teachers traveling over 10 miles.

The CPD schedule combined (i) hands-on activities, during which teachers tested UitC resources, (ii) interactive lectures, which provided relevant background information, and (iii) discussion sessions, which offered an opportunity for teachers to provide feedback and discuss best practise. The UitC project coordinator dedicated a 
week to preparing the schedule, which was used for each CPD hosted during phase 1 of the programme, and another week preparing the CPD schedule used during the second phase ${ }^{2}$

The CPD, which were attended by between 6 and 28 participants each, focussed on developing teachers' astronomical knowledge, demonstrating how to access and control the telescopes, and providing teachers with the tools to carry out lessons using the robotic telescopes, lesson guides and support materials including user guides and screen casts.

At the beginning of each teacher training session, participants are asked to fill in a survey questionnaire about their attitudes towards, and experiences, with science in their classrooms, as well as their understanding of specific astronomical phenomenon: the phases of the moon and the seasons. We evaluated their understanding of these two topics using the following questions:

1. Three of these statements about the Moon are true and three are false. Please select the three correct statements:

- The Moon's gravitational pull causes the tides on Earth

- On the same night different phases of the moon can be seen from different parts of the world

- A lunar eclipse occurs when the Moon travels into Earth's shadow

- We only ever see one side of the Moon because it does not rotate

- During the new moon phase, the Moon cannot be seen because it is in Earth's shadow

- Between new moon and half moon the Moon is mostly visible during the day

2. Three of these statements about the seasons are true and three are false. Please select the three correct statements:

\footnotetext{
${ }^{2}$ http://www.universe.wales/news/teacher-cpd/
}

- Summer occurs when the Earth is closer to the Sun

- During winter the sun is lower on the horizon

- Countries along the equator experience much smaller variations in temperature than countries closer to the poles

- The tilt of Earth's axis causes Wales to be closer to the Sun in summer than in winter

- The amount of daylight increases each day throughout the summer

- The sun rises exactly in the East and sets exactly in the West each day

The teachers in our project stated the phases of the moon and seasons were taught in their schools as part of the National Curriculum "The sustainable Earth” (Welsh Government, 2008).

Although all primary school students must learn about the phases of the Moon, only $3 \%$ of teachers answered our question on this topic correctly preceding the teacher training session, while $16 \%$ declined to answer. The teachers appeared to have an improved knowledge of the Seasons after a training workshop, but still only $13 \%$ answered correctly, with $18 \%$ declining to answer.

Teachers were also asked whether they have access to adequate resources to carry out inspiring STEM activities in their classroom. Of the 126 teachers asked, $77 \%$ stated their school did not have the resources to do this.

\section{Hands-on educational resources}

To address the lack of resources and content knowledge suggested by the survey results, and in line with the first two ESTYN recommendations to provide pupils with challenging science opportunities and support their ability to pursue their own scientific interests, UitC presented partner schools with a selection of hands-on astronomy education resources to use in their classrooms, free of charge. These included the 
following: Earth ball ${ }^{3}$ and activity booklet, Cosmos in your Pocket activity books ${ }^{4}$ (available in Welsh language), Telescope in your Pocket activity books, 'Where is Spacey's Planet?' storybook (Schilling et al., 2013), cut-out model of a 0.4-metre telescope ${ }^{6}$ and a comic named "There's no such thing as a stupid question" 7 . Resources were distributed during our teacher training sessions, where teachers were shown how to effectively use the materials to teach the content in their classrooms.

During the first phase of UitC (Jan 2014-Mar 2015), 98 schools were selected to receive an additional resource called Universe-in-a-Box ${ }^{8}$, an educational toolkit designed by the Universe Awareness project to assist educators in bringing sciences and astronomy to schoolchildren. It provides teachers and educators with over 40 practical activities covering several National Curriculum topics, as well as the materials and models to implement them. $85 \%$ of teachers asked had used the Universe-in-a-Box toolkit to teach Science within the first 6 weeks, with $58 \%$ having used it more than once, and $74 \%$ stated they would find a second Universe-in-a-Box toolkit at their school useful. A full analysis of the first phase of UitC was published in the form of a Final Report ${ }^{9}$ in 2015.

\section{Robotic Telescopes in the Classroom}

In addition to the hands-on resources, all partner schools were presented with another high-quality science education resource: access to the LCO robotic telescope network. Each school is issued a unique login that provide them with limited observing time on the $\mathrm{LCO} 40 \mathrm{~cm}$ telescopes until

\footnotetext{
${ }^{3}$ http://www.unawe.org/updates/unawe-update-1352/

${ }^{4}$ http://www.unawe.org/resources/guides/Cosmos_ Activity_Pocket_book_Welsh/

${ }^{5}$ https://issuu.com/universeintheclassroom/docs/ telescope_booklet_cover_cy-full

${ }^{6}$ https://issuu.com/universeintheclassroom/docs/ telescope_paper_model_cs5

${ }^{7}$ https://lco.global/news/ no-such-thing-as-a-stupid-question/

${ }^{8}$ http://www.unawe.org/resources/universebox/

${ }^{9}$ https://goo.gl/Gf2xpi
}

the end of the UitC programme (December 2018). The LCO account is designed to be shared by all teachers in each school and used with students during lessons.

Teachers and students are able to request observations of the night sky from a desktop computer, laptop or tablet in the classroom. Figure 2 is an example of an observation requested by primary school students and taken by one of the LCO $40 \mathrm{~cm}$ telescopes.

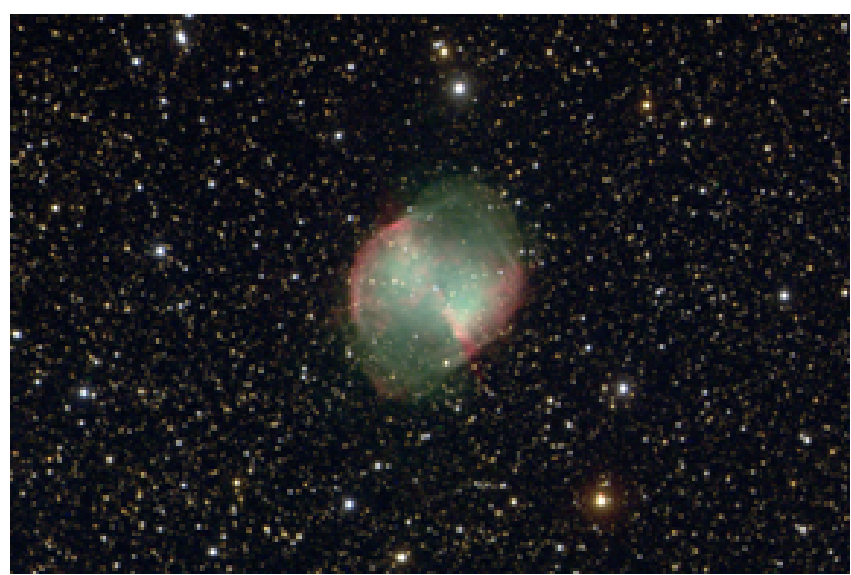

Figure 2. This true-colour observation of M27 was requested by a Year 6 student from Glyn Gaer primary school on the LCO network via the Messier Bingo tombola.

The robotic telescopes provide a complementary digital aspect to the hands-on materials, provide students ownership of their educational resources, and act as a hook to get children motivated and enthusiastic about science lessons.

The telescopes could either be used during a dedicated lesson or as a tool to enhance existing classroom activities. Dedicated lessons invited students to plan and complete an observation request using the On Sky/Valhalla interface ${ }^{10}$ or to manipulate data collected during a previous observing session ${ }^{11}$. In addition several hands-on classroom activities covering a range of topics from Geography to Art were adapted to include a robotic telescope aspect, these can be found on the Universe in the Classroom resources page and

\footnotetext{
${ }^{10} \mathrm{https}: / /$ youtu.be/dmFHAIcogKA

${ }^{11}$ https://youtu.be/HX4thuUy0Z0
} 
include activities such as Time Zones and the Human Eye vs. a Telescope ${ }^{12}$.

UitC teacher training workshops hosted throughout the second half of the programme (post-March 2015) focussed on the robotic telescopes: demonstrating how to use the telescopes, giving teachers an opportunity to request observations from the network, sharing UitC support materials and providing a space for teachers to discuss how they could use the telescopes to support learning and provide constructive feedback.

\section{Stellar Role Model Scheme (STARS)}

In addition to the teacher training sessions, UitC offered classroom workshops to participant schools hosted by enthusiastic and knowledgeable Cardiff University undergraduate and postgraduate students studying astrophysics (17), physics (25) and mathematics (8), who volunteered through our Stellar Role Model (STARS) scheme. The STARS scheme aimed to address each of the listed ESTYN recommendations, by providing additional support for teachers and engaging pupils directly using UitC resources.

The STARS programme was advertised to undergraduate and postgraduate students through various means. As UitC is supported by Cardiff University, the project coordinator was invited to advertise the programme during lectures and at events held during enrollment week events.

Departmental emails, posters and leaflets were also used.

New undergraduates and postgraduates joining the STARS programme were required to attend a training sessions at Cardiff University on outreach, education and the project resources before being given the opportunity to work with local communities across Wales. The training event included a guest lecture from an experienced primary school teacher who provided STARS with advice on working in schools and with students aged from 4-11. The STARS took part in a variation of the Space Scoop Storytelling ${ }^{13}$ activity,

\footnotetext{
${ }^{12} \mathrm{http}$ ://www.universe.wales/activities/

${ }^{13} \mathrm{http} / / / \mathrm{www}$. universe.wales/storytelling/
}

designed to challenged their creativity and allow them to practise their communication and presentation skills while utilising UitC resources.

Through the scheme, students helped to organise and run primary school workshops with the aim of inspiring and educating children, encouraging a passion for STEM and challenging negative perceptions, while demonstrating to teachers how the LCO network and other UitC resources should be used with their class (see Figure 3).

STARS were given the opportunity to work with local communities across Wales, make new friends, help improve STEM skill capacity, help improve Welsh education of STEM and motivate young children to develop a life-long enjoyment of learning. Additional benefits for STARS included:

- Role models gain valuable communication, presentation and education skills, improving their employability;

- after two events, each Stellar Role Model received a certificate endorsed by Cardiff University, which can be added to their portfolio;

- the STARS scheme was officially recognised as part of the Cardiff Award Scheme and counted towards the 70 hours of voluntary work mandatory to receive this award.

The UitC school workshops aimed to inspire in schoolchildren a curiosity about the Universe and improve their perceptions of both science and scientists. They also increased teachers' confidence in their abilities to teach science using UitC resources. $57 \%$ of the teachers asked stated that just witnessing a STARS workshop increased their confidence when using UitC resources themselves in their classroom.

By opening the project to STEM undergraduates and postgraduates we are able to offer schools a diverse pool of representatives, the 50 volunteer STARS included Welsh-speakers (5\%), female scientists (42\%) and a range of ethnic groups and 
backgrounds (10\% black and minority ethnic), The diverse STARS are then able to address representation issues (Institute of Physics, 2010) in science and broaden young children's ideas of who can be a scientist at an age where impressions can become fixed (Archer et al., 2013).

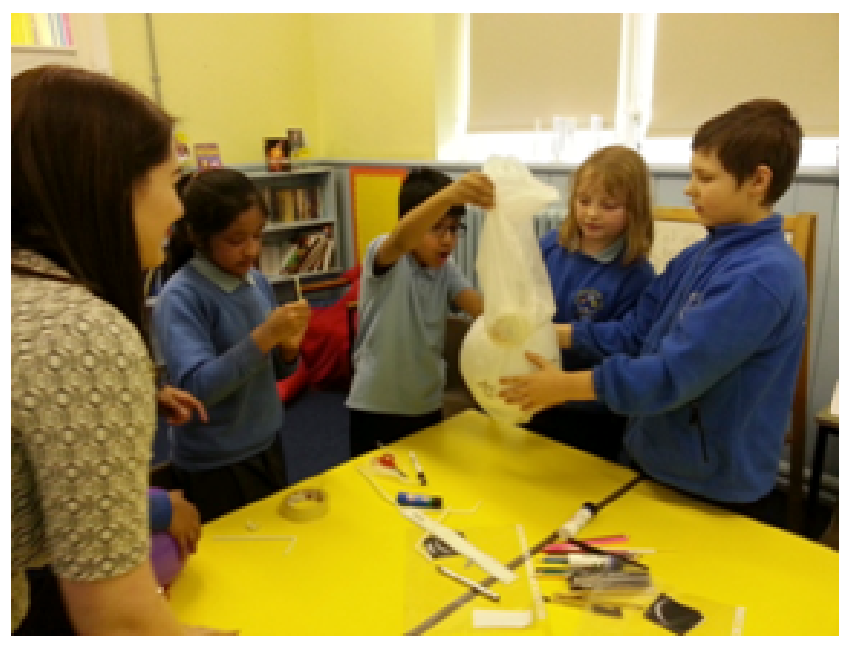

Figure 3. A Cardiff University Postgraduate Astrophysics student acts as a science role model, inspiring students, while hosting a UitC school workshop for Year 4 students at a Welsh primary school.

The scheme was not only beneficial to the school, the STARS also gained valuable communication, presentation and education skills and experience, improving their employability.

\section{Evaluation of Universe in the Classroom: effecting change in the students and teachers}

The success of UitC was evaluated by assessing the change in the students' scientific perceptions and understandings as well as through pre-and-post questionnaires completed by the teachers. The following criteria were assessed:

- the effectiveness of UitC resources, including the hands-on, paper-based and robotic telescope resources in improving STEM education;

- the extent of the students' scientific knowledge and awareness before and after attending a UitC workshop, and how it changed;

- if the diverse STARS and workshop leaders affected the students' perceptions of what a scientist looks like and does;

- whether teachers were willing and capable of using the robotic telescopes to carry out inspiring science workshops in the classrooms.

For the STARS workshops, evaluation based on pre-determined learning objectives (standard practise in formal educational) may not necessarily have assessed the new knowledge taken away by students. Instead, UitC evaluated the impact of STARS workshops using the Institute for Learning definition, which characterises learning as a change in the understanding of a key concept or idea (Falk et al., 2004). This allowed us to measure the change between students' astronomical understanding and perceptions of science and scientists, pre-and-post workshop. Two assessment tools were used: personal meaning maps (PMM) and the Draw-a-Scientist test (DAST).

\section{Personal Meaning Maps}

Personal meaning maps are a derivation of concept mapping that was first developed by John Falk (Falk et al., 2004). At the beginning of each STARS workshop, participating schoolchildren were provided with a PMM and asked to describe what they knew about the key topic of space. They could do this using words, phrases, or illustrations. Immediately after the workshop, students were asked to take another look at their PMM and to add, subtract or modify any ideas they had previously expressed. Modifications were made using a different colour pen or pencil, to make it clear which thoughts were described before the workshop and which were added post-workshop.

PMM data was then analysed qualitatively using content analysis (Bernard et al., 2016) to evaluate the range of concepts, quantity of relevant concepts and depth of understanding. Concepts were first 
grouped into the following categories: simple, complex and incorrect concepts for both pre- and post-workshop, then the number of relevant concepts per category was counted. The analysis provided insight into the extent of the students' knowledge and awareness before and after a UitC workshop, and how it changed (Figure 4).

As expected pre-workshop, simple concepts were mentioned more often than complex concepts (Figure 4). Post-workshop evaluation saw the number of complex concepts discussed by students more than triple, from 754 occurrences to 2498 , overall $76 \%$ of complex concepts mentioned were included post-workshop, while $78 \%$ of the concepts discussed pre-workshop were categorised as "simple".

These results clearly demonstrate that, the workshops were also successful beyond encouraging passion for STEM - they taught challenging concepts and provided students with a more complex vocabulary with which to describe space.

In response to the Estyn ${ }^{14}$ recommendation to "provide challenging science opportunities to stretch all pupils, particularly the more capable, and eliminate tasks that are too easy," some of the complex topics introduced in the workshops, such as the life cycle of stars and the formation of the Solar System, were still too high level for some pupils, as seen by the number of concepts incorrectly described post-workshop (63). Pre-workshop only $2 \%$ of topics were described incorrectly, the topic most often incorrectly referenced was "Other planets in the Solar System", which we defined as a simple concept. Post-workshop, the percentage of incorrect references stayed the same $(1.4 \%)$, however $98 \%$ of these were complex topics. The most challenging topics to students are shown in Figure 5.

\footnotetext{
${ }^{14}$ https://www.estyn.gov.wales
}

\section{Draw-a-Scientist Test (DAST)}

During the UitC workshops, we also utilised an evaluation tool called the Draw-a-Scientist Test (DAST), which has been widely used since 1983 (Chambers, 1983) as a tool to examine, analyse and evaluate students' and teachers' perceptions of scientists ((Finson et al., 2006); (Finson, 2002)). At the start of the workshop, students were asked to "draw a picture of a scientist." An example of a DAST can be seen in Figure 6.

The students' drawings were then analysed for the presence of stereotypical characteristics. These included the seven "standard" characteristics identified in Chambers 2010, the original developer of the DAST method. These are: lab coat, glasses, facial hair, symbols of research (e.g. beakers), symbols of knowledge (e.g. books), products of science (e.g. rockets), and captions (e.g. "eureka") (Chambers, 1983). In addition, we noted several other elements, including gender and race, plus indicators repetitively noted by students, such as famous mythical or real figures including Einstein and Frankenstein.

The gender of some of the drawings were undiscernable, and as such have been left out of the analysis shown. However, it should be noted that there may be a selection effect introduced as a result of removing this subsample.

A far smaller data set was available to analyse students' perceptions post-workshop, with just 70 entries, $11 \%$ of the pre-workshop total. These DAST were completed between 6-8 weeks after a UitC STARS workshop. While $62 \%$ of female students drew a female scientist at the beginning of UitC workshops, in the post-workshop evaluation the percentage rose to to $84 \%$. The results in Figure 7 show that female students were more likely to draw a female scientist after participating in a UitC workshop and exposure to a STARS role model, we suggest this may demonstrate the success of the role model scheme in challenging student's perceptions of scientists, breaking down the existing male scientist stereotype, and encouraging children think of themselves as scientists.

As shown in Figure 8, the students attending UitC 


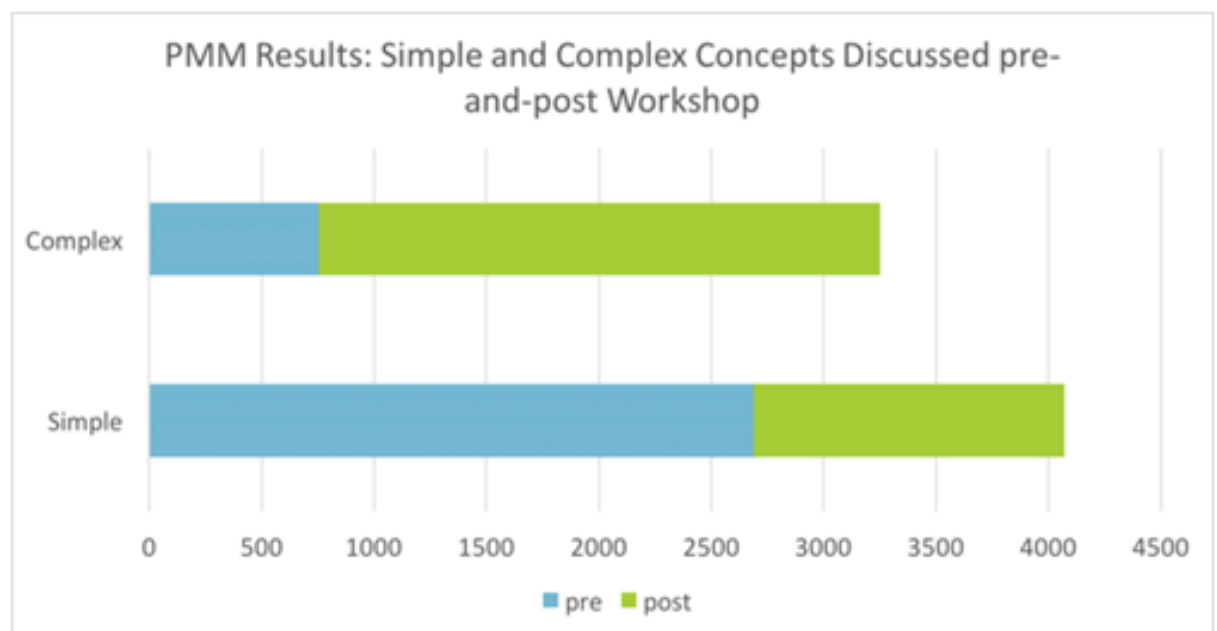

Figure 4. The plot shows Personal Meaning Maps (PMM) results pre (blue) and post (green) workshop. The concepts discussed have been split into simple concepts, such as rockets, stars, and aliens, and complex concepts, such as gravity, the expanding Universe, and the life cycle of stars.

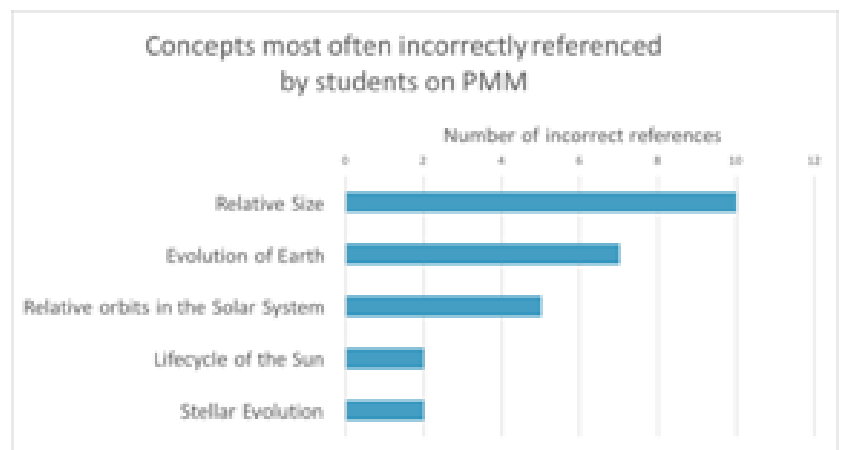

Figure 5. Students appeared to find these five complex topics the most challenging during STARS workshops. This is based on the number of students who described these concepts incorrectly on PMM. These five concepts were referenced incorrectly more often than any others.

workshops had similar perceptions of scientists as those revealed in previous studies: Caucasian males with wild hair wearing glasses and a lab coat, and working in a Chemistry laboratory ((Fort and Varney, 1989); (Huber and Burton, 1995); (Finson et al., 1995)). Figure 8 indicates that students' perceptions seem to have been altered. Whereas glasses were previously the most common feature, included by $38 \%$ students, this has been replaced by symbols of research in the post-workshop DAST, included by $71 \%$ students. This suggests a positive change in childrens' perceptions of scientists from something superficial (glasses) to seeing them as people who perform experiments and find answers.

\section{Evaluating Robotic Telescopes in the Primary Classroom}

Despite astronomy's unique inspirational qualities, encouraging teachers to use robotic telescopes in their classrooms has proven difficult, several potential deterrents have been identified and addressed by UitC:

1. lack of astronomy in the National Curriculum for Wales (National Assembly for Wales, 2013),

2. risks inherent with live observing,

3. logistical difficulties inherent with night time observing,

4. logistical difficulties inherent with observing in populated regions,

5. teachers' lack of confidence.

Here we address some of these challenges and discuss how UitC's programme was able to meet most of them. 


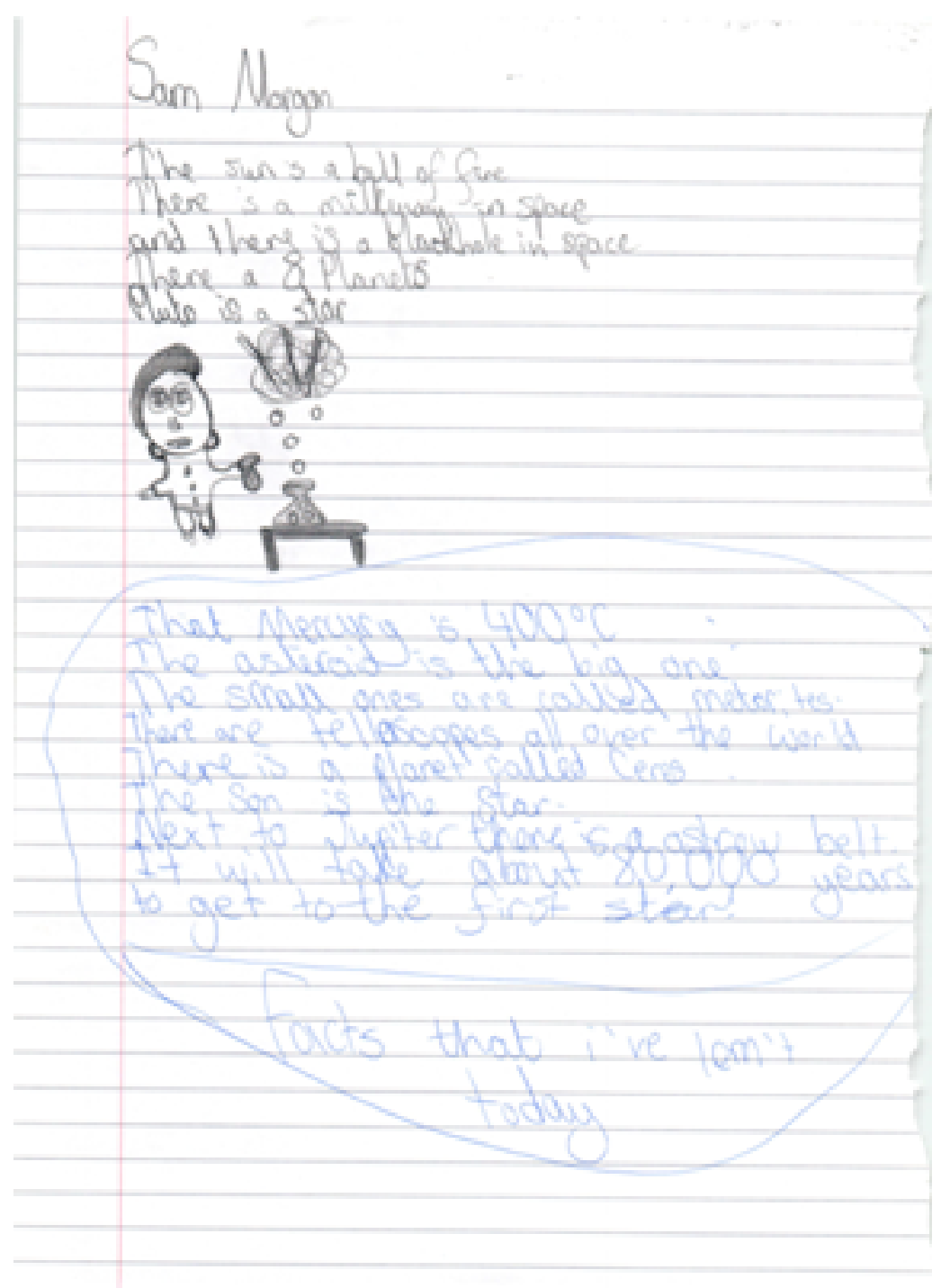

Figure 6. This is an example of a PMM and DAST created by a pupil during a UitC workshop. The text written with a pencil was included pre-workshop, whereas the text written in pen was added post-workshop.

\section{Challenge 1: Astronomy in the National Cur- riculum}

$68 \%$ of teachers surveyed during UitC teacher training events claimed to plan their lessons around the National Curriculum, however Astronomy in the Welsh National Curriculum is limited to the Solar System. In response to this, UitC provided teachers with a series of cross-curricula classroom activity guides ${ }^{15}$, that link Astronomy to a range of national curriculum topics (e.g. Time Zones, How Light Works) and utilise the telescopes as a motivational hook.

\footnotetext{
${ }^{15}$ http://www.universe.wales/activities/
}

\section{Challenge 2: Live Observing}

Participant teachers stated that live observing was preventing them from using telescopes with school children in the classroom (based on responses from the pre-teacher training survey questionnaire). However, by using the LCO network teachers may observe via a robotic scheduler, whereby the user requests an observation, which is sent to the telescope and returned at a later date via so-called "queue-based observing" (Castro-Tirado, 2010). This removes the potential of failure inherent with live observing. The observations are generally returned within a week, so they can be viewed by 


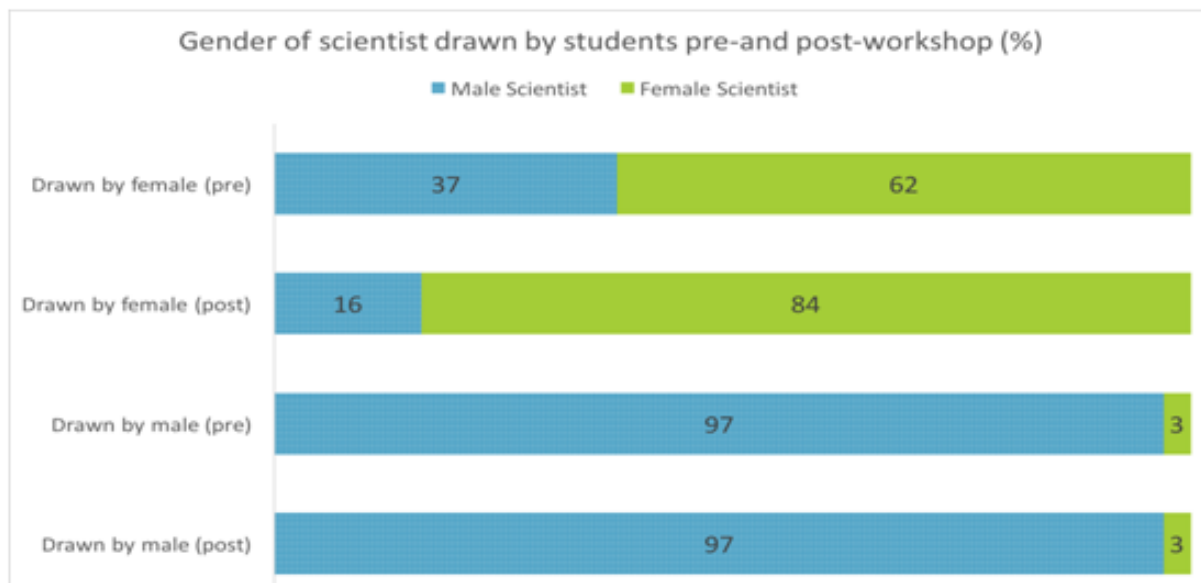

Figure 7. This graphs show the gender of scientists drawn by male and female students before and after a STARS workshop. The graph is based on evaluation collected at the start of UitC workshops, and data collected 6-8 weeks after a UitC workshop. The top bars show the percentage of male and female scientists drawn by female students, and the percentage of male and female scientists drawn by male students can be seen underneath.

the class in the same lesson slot a week after the observations were taken.

Of the observing time used by UitC teachers, $94 \%$ has been carried out using queue-based observing, much of which was done through an educational game called Messier Bingo. Messier Bingo ${ }^{16}$ is an online tombola application that incorporates observing with the LCO network, a screen shot of the tombola can be seen in figure 9 .

Messier Bingo is designed to make it as easy as possible for teachers to carry out an observing session in their classroom by incorporating the observing experience into a game. The Messier Bingo tombola seen in Figure 9 includes an LCO archive observation of each Messier object along with information about the object type, allowing the teacher to introduce students to a variety of new deep-sky objects as they play. Upon completing the game, the students may choose an astronomical target that can be observed directly from the tombola with just the click of a button.

\section{Challenges 3 and 4: Logistical Difficulties}

With the LCO network, teachers can access telescopes in different time zones, as described by

\footnotetext{
${ }^{16}$ https://messierbingo.lco.global
}

Gomez and Fitzgerald 2017, making it possible to observe the night sky during school hours, removing the logistical difficulties related to night-time observing. Each of the 21 telescopes in the LCO network is located at a world-class observing site (Brown et al., 2013), providing excellent observing conditions year round, and removing constraints faced by many schools, including light pollution and cloud cover. In addition, access to the LCO network provides schools with access to professional quality equipment at no expense.

\section{Challenge 5: Teacher Confidence}

When asked in a pre-teacher training survey to rate their confidence teaching science out of 5 (with 5 being very confident), $63 \%$ of the primary school teachers in this project rated themselves as 3 or lower. In addition, $50 \%$ of teachers stated lack of knowledge, skills or confidence as obstacles that could deter them from using the telescopes.

To overcome this challenge, UitC offered teacher training workshops to all partner schools. Of the teachers trained, 95\% said that they felt more confident using the UitC resources-including the robotic telescopes - 6 weeks after the workshop. Furthermore, after completing UitC training 


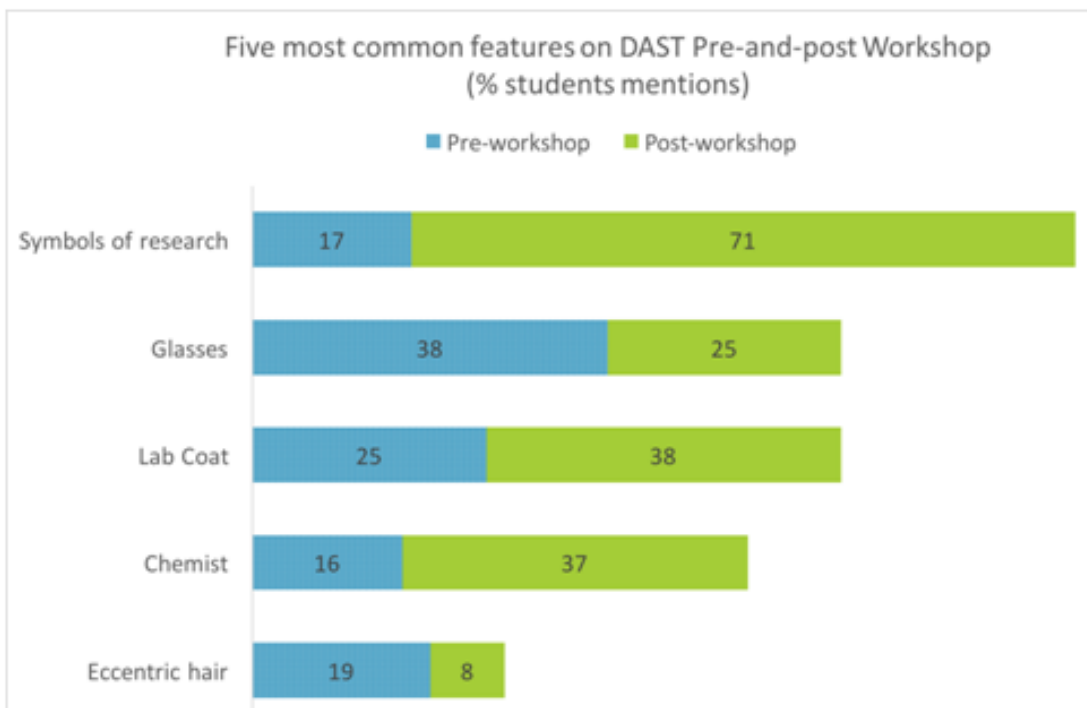

Figure 8. The graph above shows the most common five features students included on DAST. The blue regions show the percentage of student mentions of each feature pre-workshop, while the green regions show post-workshop mentions.

workshops, $25 \%$ teachers said that they have used their LCO account "several times". An additional $45 \%$ trained teachers have shared resources with other staff at their institute, with $75 \%$ stating their school could use a second LCO account.

Even after addressing each of these challenges as described, we still found UitC partner teachers reluctant to use the LCO observing interface on their own. Informal feedback showed that some teachers found the interface was too complex to be used without significant support from UitC.

To this end, we developed an interactive interface similar to Messier Bingo that provides learning opportunities that challenge children to act like scientists: observing with the telescopes, identifying target objects, analysing their observations and investigating the results. This interface, named Project Serol ${ }^{17}$, is currently undergoing beta testing and we aim to use this in the near future with our teachers to see if we can solve this final challenge.

\section{Conclusion}

Universe in the Classroom successfully engaged with the target group of under-served schools. $66 \%$

\footnotetext{
${ }^{17}$ https://serol.lco.global
}

UitC partner schools cater to a large number ( $>30 \%$ FSM students per school) of children living in relative poverty, based on FSM eligibility, while a further $47 \%$ receive below average budget per student per year. Additionally, $77 \%$ teachers stated their schools did not have the resources necessary to carry out STEM activities in the classroom. After UitC, 75\% claimed their schools would benefit from a second LCO account.

Teacher training provided an essential opportunity to boost teachers' confidence and improve the chance of the new resources being properly utilised in classrooms. Before teacher training workshops, when asked to rate their confidence teaching science, $63 \%$ of the primary school teachers in this project rated themselves as 3 or lower out of 5 . In addition, $50 \%$ of teachers stated lack of knowledge, skills or confidence as obstacles that could deter them from using the robotic telescopes with their students. However, after attending a teacher training workshop, $95 \%$ of teachers stated they felt more confident using the UitC resources, including the robotic telescopes.

The results of the DAST suggest that children as young as 7 years already appeared to hold preconceptions about scientists. However, UitC 


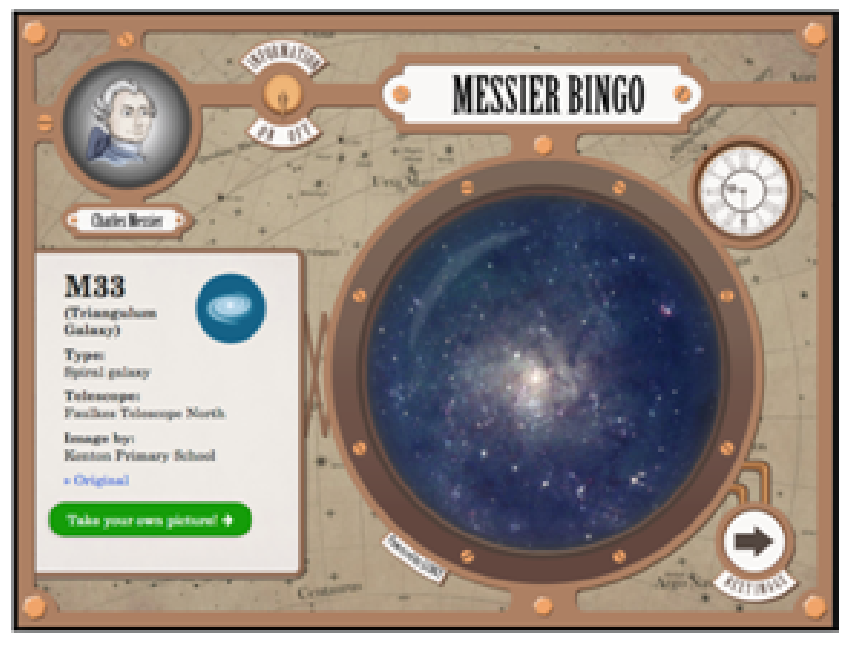

Figure 9. This image is a screen shot of the Messier Bingo tombola. The astronomical image was taken on the LCO $2 m$ telescopes located at Siding Spring observatory in Australia by pupils from Kenton Primary School. The green button on the left side of the screen allows players to submit an observation request for this object on an LCO 0.4-m telescope.

was successful in challenging these preconceptions, as demonstrated by the evaluation results: whereby children who experienced a STARS workshop changed their perception of scientists from something stereotypical (e.g. someone wearing glasses) to someone who performs experiments and finds answers. In addition, the number of children who abandoned the male stereotype by drawing a female scientist increased by more than $10 \%$ after a Universe in the Classroom workshop hosted by our diverse group of role models.

The results of the PMM evaluation clearly demonstrate that the STARSworkshops taught children challenging concepts and led them to use more complex vocabulary with which to describe space, with the number of complex topics being discussed tripling post-works.

\section{Acknowledgements}

Universe in the Classroom was made possible thanks to funding from the Welsh Government National Science Academy.
The project was run by Sarah Roberts (CU/NSA), Haley Gomez (CU) and Edward Gomez (LCOGT/CU), with our partners, Las Cumbres Observatory, Universe Awareness and See Science. We would like to express our deepest thanks to all the Cardiff University undergraduates and post-graduate role models, without whose generous time and co-operation the programme would have been impossible.

Special thanks to Chris North, Charlotte Provot, Stuart Lowe, Gabi North, Grace Sim, Pedro Russo, Hailey Llewellyn and Russell Williams and AstroCymru for their support, guidance and help delivering the project.

Haley Gomez also acknowledges support from the European Research Council (ERC) in the form of consolidator grant CosmicDust.

\section{References}

Archer, L., Osborne, J., DeWitt, J., Dillon, J., Wong, B., and Willis, B. (2013). ASPIRES: Young people's science and career aspirations, age 10 14. London: King's College, 11:119-132.

Bernard, H. R., Wutich, A., and Ryan, G. W. (2016). Analyzing qualitative data: Systematic approaches. SAGE publications.

Brown, T., Baliber, N., Bianco, F., Bowman, M., Burleson, B., Conway, P., Crellin, M., Depagne, É., De Vera, J., Dilday, B., et al. (2013). Las Cumbres Observatory global telescope network. Publications of the Astronomical Society of the Pacific, 125(931):1031.

Castro-Tirado, A. J. (2010). Robotic autonomous observatories: a historical perspective. Advances in Astronomy, pages 1-8.

Chambers, D. W. (1983). Stereotypic images of the scientist: The Draw-a-Scientist Test. Science Education, 67(2):255-265.

Estyn, Welsh Government (2013). Science in key stages 2 and 3. https://www.estyn.gov.wales /thematic-reports/science-key-stages-2-and-3june-2013, accessed 21 July 2017. 
Falk, J. H., Scott, C., Dierking, L., Rennie, L., and Jones, M. C. (2004). Interactives and visitor learning. Curator: The Museum Journal, 47(2):171-198.

Finson, K. D. (2002). Drawing a scientist: What we do and do not know after fifty years of drawings. School Science and Mathematics, 102(7):335345 .

Finson, K. D., Beaver, J. B., and Cramond, B. L. (1995). Development and field test of a checklist for the Draw-A-Scientist Test. School Science and Mathematics, 95(4):195-205.

Finson, K. D., Pedersen, J., and Thomas, J. (2006). Comparing science teaching styles to students' perceptions of scientists. School Science and Mathematics, 106(1):8-15.

Fort, D. C. and Varney, H. L. (1989). How students see scientists: Mostly male, mostly white, and mostly benevolent. Science and Children, 26(8):8-13.

Gomez, E. L. and Fitzgerald, M. T. (2017). Robotic telescopes in education. Astronomical Review, 13(1):28-68.

Huber, R. A. and Burton, G. M. (1995). What do students think scientists look like? School Science and Mathematics, 95(7):371-376.

Institute of Physics (2010). Diversity in University Physics: Statistical Digest. https://www.iop.org/ publications/iop/2010/file_43858.pdf, Accessed 21 July 2017.

National Assembly for Wales (2013). Free school meals. http://gov.wales/topics /educationandskills/schoolshome/foodanddrink/freeschoolmeals /?lang=en, Accessed 21 July 2017.

National Assembly for Wales (2016). Achievement of 15 year olds: Program for International Student Assessment national report. http://gov.wales/statistics-and-research /achievement-15-year-olds/?lang=en, Accessed 21 July 2017.
Office for National Statistics (2017). Key Stages 2-4. http://learning.gov.wales/resources/collections/keystages-2-4?lang=en, Accessed 21 July 2017.

Schilling, G., Jutte, J., and Roberts, S. (2013). Where is Spacey's planet? Amsterdam, NL: Leopold/Universe Awareness.

Statistics for Wales (2013a). Achievement and entitlement to free school meals in Wales. http://dera.ioe.ac.uk/19260/1/140122-academicachievement-free-school-meals-en.pdf, Accessed 21 July 2017.

Statistics for Wales (2013b). Key Stage 2. https://statswales.gov.wales/Catalogue/LocalGovernment/Finance/Revenue/DelegatedSchool-Budgets/delegatedschoolbudgetsperpupilby-authority, Accessed 21 July 2017.

Welsh Assembly Government (2007). Defining schools according to Welsh medium provision. Accessed 1 July 2017.

Welsh Government (2008). Science in the national curriculum for Wales. http://learning. gov.wales/docs/learningwales/publications/140624science-in-the-national-curriculum-en-v2.pdf, Accessed 21 July 2017. 